The BDJ News section accepts items that include general news, latest research and diary events that interest our readers. Press releases or articles may be edited, and should include a colour photograph if possible. Please direct your correspondence to the News Editor, Arveen Bajaj at the BDJ, The Macmillan Building, 4 Crinan Street, London N19XW or by email to bdj@bda.org

\section{New dental school to be launched in the South West}

A new dental school in the South West and 100 new permanent places for dental students in England have been given the go-ahead. The new dental school will be at the multi-campus Peninsula Medical School, a partnership between the Universities of Exeter and Plymouth and the NHS within Devon and Cornwall. The 100 new dental training places will be spread across three parts of the country. The new Peninsula dental school, with bases in Plymouth, Exeter and Truro, will have places for 62 graduate entry students per year. A joint bid from the universities of Liverpool, Central Lancashire, Lancaster and St Martin's College for dental education in Cumbria and Lancashire will take an extra 32 graduate entry places, and six places will be awarded to the University of Leeds to establish an outreach centre in Hull. Historically, Cornwall, Lancashire and Hull have all had significantly fewer dentists than the national average. Health Minister, Rosie Winterton, said: 'Although we have helped these areas with the recruitment of dentists from overseas, providing facilities for training dentists in these areas offers the best prospect of an enduring solution to these recruitment problems.'

The British Dental Association welcomed the announcement of new training places. 'The BDA has campaigned hard for extra training places for dental students and we're glad to see that we've been listened to,' said Martin Fallowfield, chair of the BDA's executive board. 'Today's announcement will help address the shortage of dentists in the UK. This is good news for the many patients who find it difficult to get dental care, though obviously the impact on this problem of today's news will not be immediate.'

\title{
The Dentaid challenge - trek the three volcanoes of Italy
}

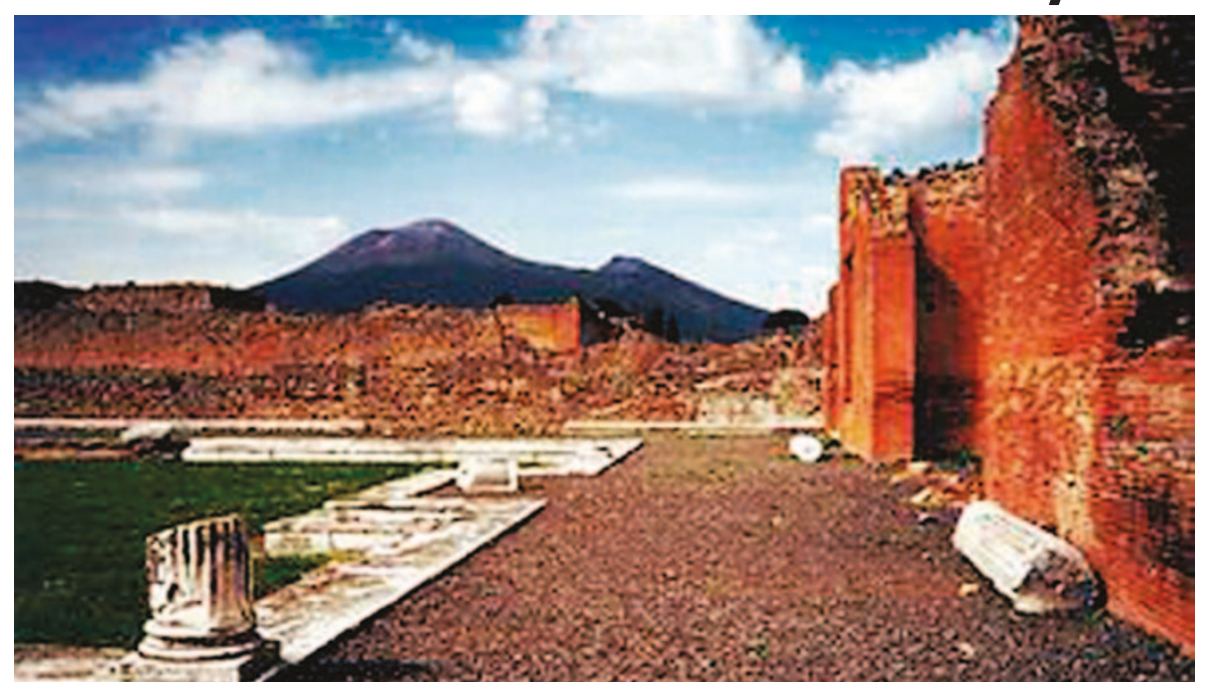

Dentaid invites you to take part in The Three Tremors challenge (9-14 September 2006). Following 2004's successful Dentaid Trek along the Great Wall of China, the charity's next challenge is in Italy, offering an opportunity to experience some of the most exhilarating natural phenomena on earth. The first day of trekking is up Mount Vesuvius, responsible for the catastrophic eruption that buried nearby Pompeii in AD 79. The team will then sail overnight to Stromboli for the climb to the summit of its volcano, which is still active and dominates the small island. In the evening there will be an opportunity to take a boat trip to watch the explosions against the night sky. On day four there is a hydrofoil transfer to Randazzo, Sicily, which dates from medieval times and is built entirely of lava rock. On day five, the team will trek up Mount Etna to the rim of one of the highest and most unpredictable of all the volcanoes. At the end of the trek there will be a transfer to the coastal town of Giardini Naxos for an overnight hotel and a celebratory dinner. Dentaid is one of the leading oral health charities in the world, improving the dental services and education of millions of people in almost 50 countries by equipping regional treatment centres, promoting school education programmes and training key workers. If you would like to support Dentaid and feel up to the Three Tremors Challenge, call Lucy Hind for an application pack on 01794324249 or visit www.dentaid.org.

\section{Saliva test}

Dr Kit Barnfather, of the Leeds Dental Institute, and his team have created a saliva test giving smokers immediate feedback on how their habit is affecting the levels of nicotine in their bodies. 'Dentists are in an ideal position to give this kind of health advice because most people regularly visit their dentist, but would only see their doctor once they already have a health problem,' said Dr Barnfather. Using a patient's saliva sample, dentists and doctors can measure the level of nicotine and breakdown products. If harmful chemicals are present the sample will change colour from yellow to brown depending on the level of chemicals. 'From this the clinician can show a patient they are absorbing high amounts of carcinogenic chemicals like tar, benzenes and so on, which could lead to oral health problems including oral cancer and gum diseases,' Dr Barnfather said.

When general health counselling on the effects of smoking is combined with this visual feedback, patients are far more likely to be successful in giving up smoking. Four in five smokers who took part in the original trial found it a helpful test. Dr Barnfather - along with researchers from the University of Birmingham - has published his findings in the $B M J$. He is now recruiting volunteers to take part in a second trial to discover whether high nicotine levels reduce the effectiveness of the antioxidant immune system in the mouth. 


\section{DIARY}

March

Bollard MiniPlate Implant \&t Distraction

Study Day

Professor Hugo De Clerck \& Dr Zvi Laster Venue: Royal Surrey County Hospital

Date: 21 March 2006

Freephone 08007833552

email sales@dbortho.com

Freefax 08007833363.

\section{April}

British Society for the Study of Prosthetic Dentistry Annual Conference

Venue: Carlton Hotel, Edinburgh

Date: 9-11 April 2006

Email:bookings@bsspd.org

www.bsspd.org

May

British Dental Conference and Exhibition Venue: International Convention Centre, Birmingham

Date: 18-20 May 2006

www.bda-events.org ( $€ 10$ discount for on-line bookings)

Registration office: 08701666625 (UK)

+44 (0) 1252771445 (overseas)

Entrance is free

10th European Congress Dentomaxillofacial radiology

Venue: Provinciehuis

Leuven, Belgium

Date: 31 May -2 June 2006

www.10ecdmfr.be

July

82nd Congress of the European Orthodontic Society

Venue: Hofburg Congress Center

Vienna, Austria

Date: 4-8 July 2006

Tel. $(+43 / 1) 53116-38$

Fax: (+43/1) $53116-61$

e-mail: azmedinfo@media.co.at

September

FDI Annual World Dental Congress

Venue: Shenzhen, China

Date: 22-25 September 2006

www.fdiworldental.org

congress@fdiworldental.org

\section{Manchester oral health pioneer wins second major honour in six months}

Professor Anthony Blinkhorn of the School of Dentistry at the University of Manchester has been awarded the $\mathrm{H}$. Trendley Dean Distinguished Scientist Award for 2006 by the International Association of Dental Research (IADR). The honour has been given for Professor Blinkhorn's ground-breaking research on public health and health services, which also earned him an OBE from the Queen just six months ago. The annual award was first presented in 1964; and is based on an academic's published research achievements over the past ten years. A global panel of past prize-winners selected Professor Blinkhorn from a host of international entrants. The award will be presented to Professor Blinkhorn at the IADR's annual scientific meeting in Australia in June.

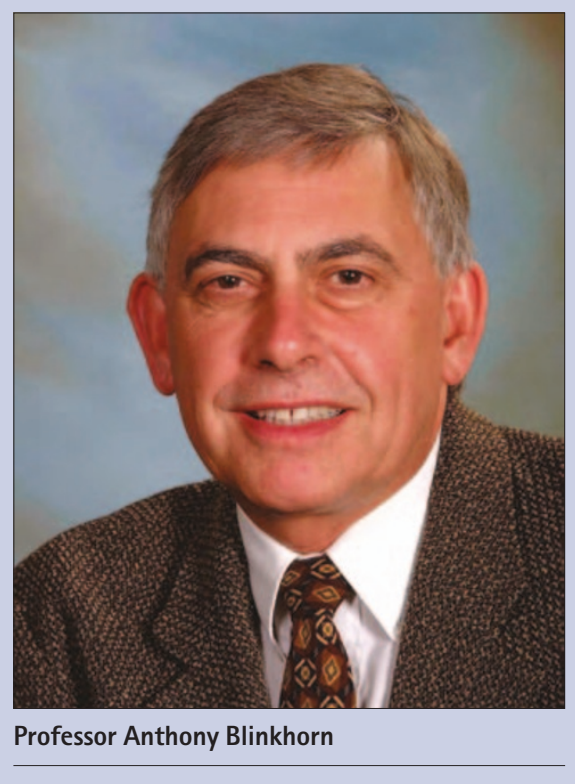

\section{A helping hand with the toothbrush}

When teachers supervise tooth brushing in primary schools, dental decay is significantly reduced. This is the finding of researchers at the Oral Health Research Centre in London. In a study, published in Caries Research, researchers reveal that daily teacher-supervised tooth brushing, reduced the occurrence of tooth decay by $11 \%$ in 5-year-old children living in a socially deprived region of London. Dental decay is one of the most common preventable health problems in children living in the poorer areas of the UK. Children living in low-socioeconomic neighbourhoods tend to start brushing their teeth at a later age, are less likely to use fluoride toothpaste and, as a consequence, experience higher levels of dental decay overall. Rates of tooth decay in five-year-olds have not improved in the last 10 years.

A total of 370 first year primary school children completed the study. Half of the children brushed their teeth once a day at school with commercially available fluoride toothpaste under the supervision of their teacher. No supplementary dietary or dental health advice was given to the children or their parents. A significant overall reduction in tooth decay was reported in all children. Looking solely at those with previous dental decay, the reduction in dental decay becomes even more apparent. A 30\% reduction in further dental decay was noted in this group. Greater protection was seen in primary teeth than in permanent teeth. It is well recognised that the introduction and use of fluoride toothpaste has been the most important factor in the general decline in dental decay in children. Regular tooth brushing with fluoridated toothpaste has a greater impact on dental health than the restriction of sugary foods and beverages.

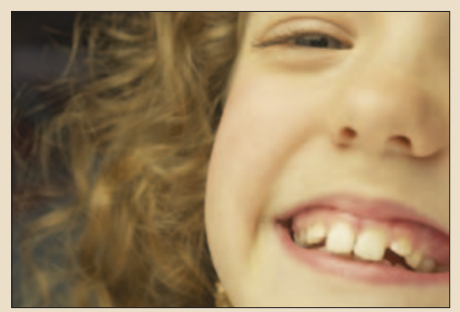

\section{Mogjan Azari struck off}

The General Dental Council has barred Mogjan Azari from practising dentistry in the UK. Azari, a principal at two dental practices in south London, allowed her unqualified boyfriend, Omid Amidi-Mazaheri, to work on over 600 patients. Amidi-Mazaheri, drilled cavities without anaesthetic and gave patients fillings that crumbled within days. Many of the patients suffered excruciating agony. One patient accused Amidi-Mazaheri of dropping an instrument down his throat while he administered an injection. The couple also defrauded the NHS of about $£ 30,000$ for non-existent procedures. In March 2005, Southwark Crown Court found Azari guilty of obtaining money by deception. She was jailed for one year. Amidi-Mazaheri, an Iranian national, received a two-year sentence after admitting similar offences. 


\section{News from the BDA}

\section{Meeting with DoH}

A BDA team led by Lester Ellman, Chair, General Dental Practitioners Committee, met with officials from the Department of Health 25 January to discuss some urgent issues arising from contact the BDA has had with members about the way in which contract discussions are taking place at local level. There was a forthright exchange of views about the calculation of UDAs and about the extent to which PCTs are currently able to use local discretion in resolving issues relating to practitioners who have an atypical 'test year'. The BDA is continuing to develop advice on a range of contractual issues and this will be posted on the website and published through BDA News as soon as it is available.

\section{Parliamentary issues}

The first adjournment debate of 2006 at the House of Commons focussed on NHS dentistry. Nineteen MPs discussed the issue, with many of them criticising the new GDS contract for failing to deal adequately with workload. Also debated were time and quality issues, historic under-funding of NHS dentistry, arguments in favour of NHS golden handcuffs for dental graduates, concern about PCTs' abilities to manage primary dental care commissioning and cuts in PCT budgets affecting orthodontic provision and referrals to secondary services. BDA briefings were given to a number of MPs, including Parliamentary Panel members, before the debate.

\section{Converting to private practice seminar sold out}

The first BDA private practice seminar was held in London in late January, with 97 delegates. The morning session saw presentations from the BDA's Darshan Patel, Arun Mehra of Samera Ltd and Philip Newsome of the University of Hong Kong. The afternoon covered ethical selling and practice retailing and dispensing, with contributions from selling coach Ashley Latter and Chris Gull, a GDP from Brighton.

\section{Welsh Assembly debates dentistry}

The Welsh Assembly has also spent several hours discussing NHS dentistry. The main highlights saw the Health Minister, Brian Gibbons, triumph the success of the PDS schemes in increasing patient registration and $£ 7 \mathrm{~m}$ being allocated to dentists through the Welsh dental initiative grant scheme. Opposition Assembly Members (AMs) were united in their criticism of the proposed new contract, arguing that Denplan was proving to be the main recipient of disaffected dentists. There was a call for more preventionled aspects to the new contract, increased oral health promotion schemes and screening in schools. A number of AMs took issue with overall workforce numbers, including pleas for increased undergraduate places, and called for the Welsh Assembly Government to recognise the profession as an ageing one. The BDA had briefed all opposition health spokespeople ahead of the debate.

\section{BDA leading the way in answering dentists' questions on new contract}

Advisers from the Professional Services Directorate have been speaking at specially arranged workshops to give practitioners the facts and answer questions about the new GDS arrangements. The courses have been and continue to be organised via LDCs, BDA Branches and Sections.

Meetings have been held in Leicester, Leeds, Barnet, Lincoln, Norfolk, Croydon, Basingstoke, Hertfordshire, Staffordshire and Portsmouth. More meetings continue to be organised for this month and beyond.

\section{Select Committee grilling for Minister}

Dentistry Minister Rosie Winterton faced scrutiny by the Health Select Committee on her ministerial responsibilities in a two-anda-half hour session dominated by two portfolio responsibilities patient and public involvement and dentistry.

Dentistry questions focused on issues including: workforce planning, the much publicised five per cent reduction in number of courses of treatment, and guaranteed funding commitment and patient registration levels. They also covered the future of Dental Access Centres, water fluoridation and the lack of guidance and leadership from the Department of Health, how the UDAs and patient charge bands correspond, and the desire for more efficiency within the system. The BDA had briefed the Committee beforehand.

\section{Allocation of dental premises funding}

The end of January saw the Scottish Executive announce the allocation of premises funding for clinics, access centres and hospitals. In its reaction to the announcement, the BDA stressed that if the Scottish Executive is serious about solving the problems facing NHS dentistry in Scotland, it must work constructively with the nation's general dental practitioners; the providers of 80 per cent of dental care in Scotland.

\section{New publication on child protection}

The BDA has agreed to support a DoH-funded but independently produced and refereed publication on child protection to go to all dental teams. A handbook, to be published later this year, will be supported by a website that will provide practical information in an easily digestible form. The BDA's name and logo appear on the back cover, together with that of the Faculty of General Dental Practitioners. 


\section{Contract will fail patients, BDA warns Minister}

As the $B D J$ went to press, the BDA demanded an urgent meeting with Health Minister Rosie Winterton to discuss fears about the impact on patients of the new contract.

Lester Ellman, Chair of the BDA's General Dental Practice Committee (GDPC), will tell the Minister that the contract will fail to achieve the Government's aims of improving patients' access to dentistry, improving the nation's oral health and raising the quality of patient care. The 1 April 2006 changes to NHS dentistry are untested and the new monitoring of targets (counting 'units of dental activity' - UDAs) is causing confusion across the NHS which is unable to cope with the new arrangements, said Dr Ellman.

"The situation is a shambles for both patients and the profession. Our fear is that the new contract will do nothing to improve access to care for patients or improve the quality of care. The Government claims to be committed to preventive care yet that does not seem to apply to dentistry. We're now faced with a contract that puts dentists on a new treadmill and means they can't give the care and time that they want to give to patients. This is bad for patients, bad for dentists and disastrous for NHS dentistry."

Dr Ellman will call for a suspension of the UDA system and a consultation with dentists on other options to be tested and demonstrated to work. He will also demand a review of the contract, once operative, to assess its impact on patient care.

The GDPC supported a motion approved by the BDA's Representative Body (28 January) that "The BDA believes that the Government's aims of securing patient access, improving oral health and raising the quality of patient care will not be achieved by the imposition of this target driven NHS contract."

For the latest on the NHS changes, including information on explaining the reforms to patients, please visit the BDA website at www.bda.org.

\section{University dentist wins top prize}

A clinical lecturer from the University of Birmingham School of Dentistry has become the first British winner of a prestigious research prize awarded by the European Society of Endodontology. Phillip Tomson a lecturer and specialist registrar in restorative dentistry won the Wladimir Adlivankine European Society of Endodontology Research Prize for his work into using a new material to protect the pulp in grossly decayed teeth. Phillip was presented with the award at the Society's biennial conference at Trinity College Dublin.

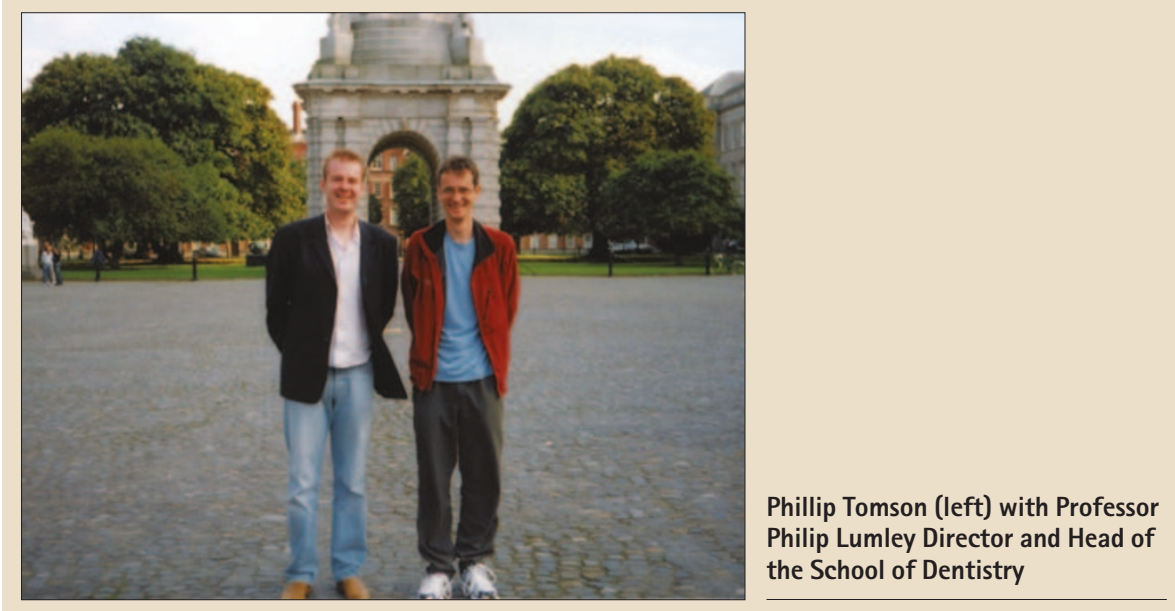

\section{DCP registration - last call for views}

The General Dental Council (GDC) is on track to open its new register for dental care professionals (DCPs) in July 2006. In the lead up to this, the GDC has made a final call for views on the DCP registration system and how it will all work in practice. The consultation is on the draft Rules - in other words, the subsidiary legislation that details the policies for DCP registration.

The Rules cover issues such as the routes of entry on to the register for the different DCP groups, the registration fee (how much it will be and incentives for early registration), and the titles DCPs will be able to use. Although much of the policy for DCP registration is covered in these draft Rules, some aspects of policy, such as the professional relationships between different members of the dental team, is covered in the GDC's new ethical guidance, and some, such as the tasks which members of each group should be competent to carry out, in new educational curricula.

'DCP registration is one of the most significant devel-

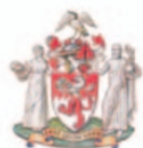

General Dental Council opments in dentistry in the last 50 years and will affect all dental professionals,' said Hew Mathewson, president of the GDC. 'This current consultation is a further opportunity for you to have your say on how it will work.' The consultation on the DCP registration draft Rules is posted on the GDC website at www.gdc-uk.org. The deadline for responses is Friday 31 March 2006.

\section{New admission test for future dentists}

From summer 2006, candidates applying to the dental and medical schools of 24 UK universities, for entry in 2007, will be required to take the UK Clinical Aptitude Test (UKCAT). The test will help universities make more informed choices from amongst the applicants. It will help ensure that the candidates selected have the best combination of mental abilities, attitudes and professional behaviours required for doctors and dentists to be successful in their clinical careers. The 90-minute computer-based test will require no specific preparation as it aims to probe innate skills and competencies. Candidates will be able to choose from over 150 UK test centres, so that they can sit a test near their home, school or college. No UK applicant should be more than 40 miles from a test centre and $80 \%$ will be within 20 miles. 


\section{Liquorice root may help fight tooth decay}

Compounds isolated from liquorice root may help prevent cavities, according to researchers at the University of California, Los Angeles. In test tube studies, the scientists showed that an extract from a plant root that is used to make liquorice sweets and other products contains at least two compounds that appear to be potent inhibitors of Streptococcus mutans, a major cause of dental caries. Their study appears in the latest edition of the Journal of Natural Products, a monthly peer-reviewed joint publication of the American Chemical Society and the American Society of Pharmacognosy.

More studies are needed before it is proven that the compounds effectively fight cavities in humans, caution the researchers. However, if further studies show promise, the liquorice compounds could eventually be used as cavity-fighting components in

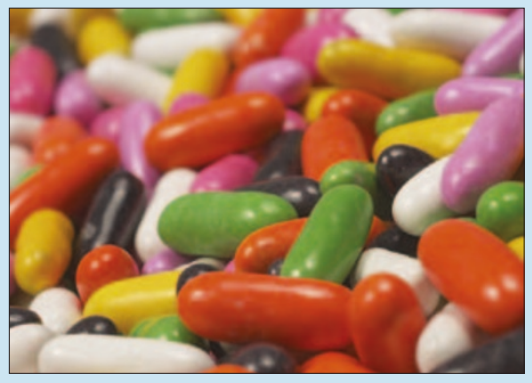

mouthwash or toothpaste. Liquorice has been an important herb in Chinese medicine for many years and is now being rediscovered by Western medicine as a rich source of potentially beneficial compounds. In addition to being used as flavouring and sweetening agents in sweets, tobaccos and beverages, compounds derived from liquorice root have been shown to help fight inflammation, viruses, ulcers and even cancer.

\section{Cardiff dental researchers tackle childhood tooth decay}

Researchers in Cardiff University's School of Dentistry are looking to improve the dental health of the nation's children. They are conducting research in nurseries and primary schools in Cardiff and hope to identify barriers to and opportunities for oral health promotion amongst children. 'Although the oral health of older children in Wales has improved over the last 20 years, dental decay in young children remains a significant problem," said lead researchers, Dr Ivor Chestnutt. 'More than half of all children have tooth decay, severe enough to require either a filling or an extraction before they start school, and the problem is greatest in areas of social and economic disadvantage.'

Working with partners from Cardiff and Vale NHS Trust's Community Dental Service and Cardiff schools, the research is designed to identify how a holistic approach to the health and well-being of children can be developed to include practices leading to good oral health. The project will also identify how nursery and school nutrition policies impact on both oral and general health and how other oral health promotion activities, such as tooth brushing programmes, can be targeted at those children at greatest risk of oral disease.

'Too frequently, young children's first experience of dental care is when they are brought to the dentist having been awake all night with toothache,' said Dr Chestnutt. 'There is often little alternative but to administer a general anaesthetic and extract decayed teeth - a horrendous introduction to dentistry. This project will enable us to identify how factors such as snack and drink policies can be modified to impact positively on health and how Health and Education sectors can work together to improve the oral health of those children in Cardiff who are still suffering unacceptably, from what is a preventable disease.'

\section{Lindsay Society elections}

At the Lindsay Society for the History of Dentistry's AGM, Dr. Bob McKecknie from Paisley was elected Chairman Elect to take the Chair in 2006, and Professor S.Gelbier took on the position of editor of the Society's 'The Dental Historian'. The editor would welcome enquiries from potential contributors to the journal, whilst membership enquiries should be made to the secretary Stuart Robson on 01904 794929, or through the BDA Museum at Wimpole Street.

\section{Poverty and periodontal disease}

In America, it has been found that severe periodontal disease is more frequent in poorer populations. Socioeconomic disadvantage at the individual and neighbourhood level is associated with severe periodontitis among African-Americans and whites, according to research conducted at the Mailman School of Public Health and reported in the American Journal of Public Health.

The study, based on a sample of people aged 45 to 64 , found that low income was associated with the prevalence of severe periodontitis among whites, and both low education and income levels were associated with severe periodontitis among African-Americans. 'These associations remained significant after adjustment for age, gender, recruitment centre, and neighbourhood socioeconomic conditions,' said Luisa N. Borrell, lead author of the paper. 'Specifically, the odds of having severe periodontitis were twice as high among African Americans without a highschool diploma than among their peers with a college degree or postgraduate education. Moreover, low income African Americans and whites were at least 50\% more likely to have severe periodontitis than their high-income counterparts.'

This is the first study of its kind to investigate neighbourhood effects on periodontal disease, although it had been assumed that area of residence influences a person's health behaviours. 'In the case of periodontal disease, social contexts could promote or prevent behaviours that may affect periodontal health such as smoking, regardless of individual socioeconomic status,' said Dr. Borrell.

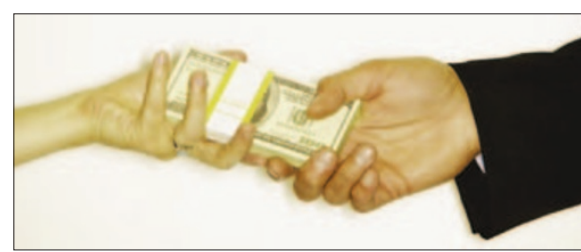

\section{New service for jobseekers}

A new website for dental technicians and dental students will be launched later this year. The website, Looking for Dental (www.lookingfordental.com) allows jobseekers to present themselves online. As well as letting students upload their technical expertise, the website will also allow students to upload photographs of their best work to show to potential employers. The system is currently being tested, and will be launched in April 2006. The service is free for jobseekers. 